The International Journal of Indian Psychology

ISSN 2348-5396 (e) | ISSN: 2349-3429 (p)

Volume 5, Issue 1, DIP: 18.01.045/20170501

DOI: $10.25215 / 0501.045$

http://www.ijip.in | October-December, 2017

Research Article

\title{
Hypertension Knowledge Test: Development and Validation
}

\author{
Asher Andrew ${ }^{1}$, Meena Hariharan ${ }^{2} *$
}

\section{ABSTRACT}

This paper discusses the process of development and validation of Hypertension Knowledge Test on a total sample of 614 hypertensive patients recruited in three stages. Standard procedure of test development was followed. The final form of the test consisted of 22 items hierarchically arranged following the criteria of item difficulty and item discrimination. The test measures four dimensions of knowledge viz. General awareness, Lifestyle, Causes, Care, Casualty awareness and Management of medication. The test-retest reliability was 0.92 $(\mathrm{p}<.001)$.The construct validity measured by correlating hypertension knowledge scores with Blood Pressure readings was highly significant $(\mathrm{p}<0.01)$.

Keywords: Hypertension Knowledge Test, HKT, Knowledge of Hypertension, Test Development, Test Validation, Illness Cognition.

In the recent times, there is a mercurial rise in the incidence of hypertension. World Health Organization estimates that one in three adults aged 25 or above or about one million people are affected by hypertension (World Health Organization, 2013). The alarming proportion of 29.8\% prevalence of hypertension in India (Anchala et al., 2014) is a signal to the health sector to plan interventions aimed at prevention and management involving all age groups with the future generations in view. This has to be the top priority in view of the fact that uncontrolled hypertension leading to cardiac emergencies and sometimes leading to cardiac deaths are avoidable with simple appropriate steps related to health literacy. Globally, hypertension levied a considerable economic burden of 10 percent of expenditure on health care (Gaziano, Bitton, Anand, Weinstein, 2009) which underlines the serious implications for developing countries with constrained economic resources. As such, Health economy figures India indicate a greater burden of annual income losses incurred due to cardiovascular diseases and hypertension translating to more than one third of all income losses (Mahal, Karan, \& Engelgau, 2010). In addition to economic losses, Hypertension also impacts the productivity of an individual. A Global Burden of Disease Study conducted by Limet al.(2013) reports hypertension contributing to 7 \% Disability Adjusted Life Years (DALYs) across the world .

\footnotetext{
${ }^{1}$ UGC, Senior Research Fellow, Centre for Health Psychology, University of Hyderabad, Telangana State, India

${ }^{2}$ Prof. \& Head, Centre for Health Psychology, University of Hyderabad,Telangana State, India

*Responding Author

Received: October 10, 2017; Revision Received: November 01, 2017; Accepted: November 23, 2017

(C) 2017 Andrew A, \& Hariharan M; licensee IJIP. This is an Open Access Research distributed under the terms of the Creative Commons Attribution License (www.creativecommons.org/licenses/by/2.0), which permits unrestricted use, distribution, and reproduction in any Medium, provided the original work is properly cited.
} 


\section{Hypertension Knowledge Test: Development and Validation}

In this background, regulating the blood pressure and managing it appropriately is the need of the hour. Management of hypertension involves minimizing risk behaviours and optimizing health promoting behaviours. Any voluntary behavioural change in adult is desirable in view of probability of sustenance. Voluntary change in health risk and health promoting behaviour calls for a strong conviction. The conviction gains its origin and strength from a robust cognitive base.

Cognitive base is created through appropriate knowledge inculcation. Learned resourcefulness model (Rosenbaum, 1990) theoretically proposed that cognitions impact the self-control of health behaviour of a patient thereby the blood pressure control. Many intervention studies supported that with the increase in patients' knowledge, the hypertension control also increased (Wang et al., 2003;Panditet al., 2009; Xuet al., 2014). However, the research evidence on this essential knowledge level in patients rings an alarm for public health sector. It was found that patients did not understand the importance of the therapies in the management of their disease conditions (Ponnusankar, Surulivelrajan, Anandamoorthy, \& Suresh, 2004); importance of regular clinic visits (Lawson, Lyne, Harvey, \& Bundy, 2005), felt that medications need to be taken only when the symptoms are severe (Bender and Bender, 2005). Their knowledge about the disease, its management and the consequences of poor adherence were found to be very poor (Alm-Roijer et al, 2004); knowledge about the consequences of uncontrolled hypertension was also found to be poor (Wexler, Elton, Taylor, Pleister, \& Feldman , 2009). Past research has reportedly emphasised the significance of patient education for effective chronic care management (Bodenheimer, Wagner, \& Brumbach, 2002; Coleman, Austin, Brach \& Wagner, 2009). It is desirable that patient education programmes are so planned to build upon the existing knowledge and address the misconceptions that requires unlearning before being substituted with right knowledge.

In order to measure the efficacy of the patient education programs, several studies have adapted the pre-existing tools to meet their study objectives, however these adapted tools could not be used across other studies (Sanne, Muntner, Kawasaki, Hyre, \&DeSalvo, 2008); some others tools were specific to measuring particular domain of hypertensive knowledge such as knowledge about risk factors alone (Shaikh et al., 2011) and knowledge about hypertensive complications (Ghembaza, Senoussaoui, Kendouci Tani, \& Meguenni, 2014), knowledge about medication alone (Ponnusankar et al., 2004). Few other tests lacked uniform response (Han et al., 2011; Schapiraet al., 2012).

Therefore, development and standardization of instruments to measure knowledge of hypertension are the need of the hour. The procedure of standardization should adhere to the standard procedures involving steps such as item writing, item analysis, reliability, validity testing (Baliz-Erkoc, Isikli, Metintas, \& Kalyoncu, 2012), factor analysis where appropriate (Hariharan, Chivukula, \& Rana, 2015; Hariharan, Thomas, \& Rana, 2015) or base on item response theory (Han et al., 2011). 
To our knowledge, several studies have used instruments that assessed the individual's knowledge about hypertension. However, psychometric properties were not established for majority of them. (Kusuma, Gupta, \& Pandav, 2009; Ponnusankar et al., 2004; Ramachandran, Wu, Kowitlawakul, \& Wang, 2016;Sanne et al., 2008; Viera, Cohen, Mitchell, \& Sloane, 2008; Williams, Baker, Parker, \& Nurss, 1998) and tested on samples as small as 90 (Kusuma et al., 2009). Out of twelve studies reviewed, only four studies (BalizErkoc et al., 2012;Han et al., 2011; Peters, \& Templin, 2008;Williams et al., 1998) reported the internal consistency reliability i.e. coefficient alpha ranging from .70 to .90 and four studies (Baliz-Erkoc et al., 2012;Han et al., 2011; Peters ,\& Templin, 2008; Schapira et al., 2012) reported the validity of the instruments.

In this paper, we report the development and validation of the test named as Hypertension Knowledge Test (HKT).

\section{Development and validation of the Hypertension Knowledge Test}

The entire process of developing and validating the test is described under four phases viz. Phase I-Item writing and content validation, phase II — Item analysis, Phase III—Reliability testing, Phase IV-Validity testing.

\section{PHASE I-ITEM WRITING AND CONTENT VALIDATION}

In order to identify the essential aspects a hypertensive patient needs to know related to his/her condition, a thorough review of literature was carried out. Articles related to causes, consequences of uncontrolled hypertension, management of hypertension, lifestyle modification, medications and symptoms of hypertension were reviewed. In addition to research articles, the Joint National Committee's panel (JNC-8) guidelines for management of Hypertension in adults (James et al., 2014), patient education reports on high blood pressure by the University of Maryland Medical Center (2017), and American Heart Association's online test (test your blood pressure IQ, 2017) were critically reviewed. Apart from literature review and other documents, discussions were held with General Physicians and Cardiologists on the essential, desirable and value added knowledge domain for the patients diagnosed with primary hypertension. Based on the above, items were written down in the form of statements/question along with multiple choice answers. A total of 30 statements related to the cause, symptoms, management, lifestyle and repercussions of neglecting hypertension were written for the new test in English and also translated to the local language and followed by expert panel back translation.

\section{Content validation}

In order to identify and retain the essential items and discard those which are not relevant, a list was prepared which consisted of 30 items that were written in a proforma having two columns namely essential and non-essential against each item. This list was given to a panel of five experts (two Health Psychologists and three Medical Doctors). The experts were asked to mark each item as 'essential' or 'non-essential'. The items that were marked as 


\section{Hypertension Knowledge Test: Development and Validation}

essential by all the experts were retained. Based on this criterion, 24 out of 30 items were retained.

\section{PHASE II-ITEM ANALYSIS}

Item analysis was carried out in order to evaluate the item characteristics of each item of the Hypertension Knowledge Test. Two types of item analysis such as item difficulty index and item discrimination value were calculated on the obtained data. The objective of assessing difficulty index for each item was to arrange them accordingly in the increasing order of the difficulty and also to drop the items that are extremely easy or extremely difficult. In addition, Item discrimination index, which is a basic measure of the validity of an item, was calculated in order to measure the ability of each item to discriminate between those who scored high on the total test score and those who scored low. This index showed the extent to which overall knowledge of the hypertension is related to the response of an item and also to ascertain whether the test taker got an item correct due to their level of knowledge of hypertension and not due to chance or test bias.

\section{METHOD}

\section{Participants}

A total of 150 hypertension patients were included at this stage following convenience sampling. The inclusion criteria were patients having the diagnosed condition of primary hypertension for at least one year prior to the study and able to read English or the local language. In the sample, $60 \%$ of the participants were men and $40 \%$ were women. They included school dropout (32.5 \%),high school education (32.5\%), and graduation and above (34.4\%). The age range was 30-65 years $(M=52.17, S D=8.54)$. The mean duration of illness was 6.42 years $(S D=5.63)$.

\section{Procedure}

The study procedure was approved by the institutional ethics committee of the University of Hyderabad (Approval number UH/IEC/2014/22). The patients were selected from the health Centre of a church from the state of Telangana when they visited for monthly consultation. Patients were approached and those who have given informed consent were recruited for the study. The newly developed Hypertension Knowledge Test-1 consisting of 24 items was administered individually when the participant was seated in the waiting lounge of the health Centre. The assessments took 20 to 25 minutes.

\section{RESULTS}

The obtained quantitative data were analyzed by using IBM SPSS Statistics 20 for item analysis. Two methods were used for item analysis-(i) item-difficulty value ( $p$ ), and (ii) item-discrimination value $(d)$. These values were taken as criteria to identify relevant items for the test.

Item-difficulty value: The formula to calculate the item-difficulty value(Crocker and Algina 1986) is: $p=N_{p} / N$; where $\mathrm{N}_{\mathrm{p}}$ indicated the number of test takers in the total group who answered the item correctly and $\mathrm{N}$ denoted the total number of test takers in the group. On the 


\section{Hypertension Knowledge Test: Development and Validation}

basis of the formula the item-difficulty value $(p)$ was calculated for each item of the test and is presented in Table 1.

Table 1 Item-difficulty value (p), and item-discrimination value (d) of the 24 items

\begin{tabular}{|c|c|c|c|}
\hline SN & DIMENSIONS \& QUESTIONS & $\begin{array}{l}\text { DIFFICULTY } \\
\text { INDEX }(p)\end{array}$ & $\begin{array}{l}\text { DESCRIMINATION } \\
\operatorname{INDEX~}(d)\end{array}$ \\
\hline \multirow[t]{8}{*}{ I } & General awareness: & & \\
\hline & $\begin{array}{l}1 . \quad \text { Hypertension is called as silent killer } \\
\text { because }\end{array}$ & 0.27 & 0.12 \\
\hline & $\begin{array}{l}2 . \quad \text { Once someone has high blood } \\
\text { pressure, it usually lasts for }\end{array}$ & 0.77 & 0.32 \\
\hline & 3. The fact about High blood pressure is & 0.62 & 0.61 \\
\hline & Hypertension except & 0.38 & 0.29 \\
\hline & $\begin{array}{l}5 . \quad \text { Hypertension is blood pressure } \\
\text { recording more than }\end{array}$ & 0.50 & 0.12 \\
\hline & $\begin{array}{l}\text { 6. High B.P is called Primary } \\
\text { hypertension when }\end{array}$ & 0.47 & 0.17 \\
\hline & $\begin{array}{l}7 . \quad \text { If someone's blood pressure is } \\
120 / 80 \text {, it is }\end{array}$ & 0.88 & 0.17 \\
\hline \multirow[t]{6}{*}{ II } & LIFESTYLE & & \\
\hline & $\begin{array}{l}8 . \quad \text { Risk of hypertension can be reduced } \\
\text { by }\end{array}$ & 0.60 & 0.54 \\
\hline & $\begin{array}{l}\text { 9. life style modifications for treating } \\
\text { Hypertension include }\end{array}$ & 0.44 & 0.63 \\
\hline & $\begin{array}{l}\text { 10. Dietary changes that are useful to } \\
\text { control hypertension }\end{array}$ & 0.81 & 0.34 \\
\hline & $\begin{array}{l}\text { 11. For patients with high B.P, reducing } \\
\text { salt intake. }\end{array}$ & 0.77 & 0.39 \\
\hline & $\begin{array}{l}\text { 12. Which of the following statement is } \\
\text { wrong? }\end{array}$ & 0.44 & 0.49 \\
\hline \multirow[t]{8}{*}{ III } & CAUSES,CARE,CASUALITY & & \\
\hline & AWARENESS: & & \\
\hline & Hypertension is caused because of & 0.64 & 0.39 \\
\hline & $\begin{array}{l}\text { 14. Damage caused by high blood } \\
\text { pressure to body }\end{array}$ & 0.37 & 0.34 \\
\hline & $\begin{array}{l}\text { 15. What happens when B.P shoots up } \\
\text { very high crossing its limits }\end{array}$ & 0.77 & 0.37 \\
\hline & $\begin{array}{l}\text { 16. Doctor needs to be informed about } \\
\text { the medicines that a B.P patient is using } \\
\text { when }\end{array}$ & 0.73 & 0.37 \\
\hline & 17. Warning signal during a heart attack & 0.55 & 0.73 \\
\hline & $\begin{array}{l}\text { 18. In a patient of Hypertension, If } \\
\text { suddenly one side of face starts drooping, } \\
\text { speech becomes difficult, arm becomes weak } \\
\text { then its possibly }\end{array}$ & 0.58 & 0.46 \\
\hline \multirow[t]{2}{*}{ IV } & MANAGEMENT: MEDICATION & & \\
\hline & $\begin{array}{l}\text { 19. People with high blood pressure } \\
\text { should take their medicine }\end{array}$ & 0.77 & 0.54 \\
\hline
\end{tabular}




\begin{tabular}{llcc}
\hline SN & DIMENSIONS \& QUESTIONS & $\begin{array}{c}\text { DIFFICULTY } \\
\text { INDEX }(\boldsymbol{p})\end{array}$ & $\begin{array}{c}\text { DESCRIMINATION } \\
\text { INDEX (d) }\end{array}$ \\
\hline 20. Commonly used drugs to treat & 0.56 & 0.49 \\
hypertension & & 0.59 & 0.59 \\
21. Medicines for hypertension & 0.55 & 0.54 \\
22. Which one of the following is wrong & 0.53 & 0.32 \\
23. Which of the following is correct? & 0.55 & 0.59 \\
24. What should be done if a person & & \\
misses a dose of medication? &
\end{tabular}

Note: $p$ denotes difficulty index and $d$ denotes discrimination index

None of the items were deleted based on item-difficulty value $(p)$ as all the items were well in the cut-off range of .10 to .90. Therefore all the items were remained.

Item-discrimination value :Item discrimination value $(d)$ was calculated for each item by identifying $27 \%$ top scorers and $27 \%$ bottom scorers (Kelley 1939). The formula to calculate the item-discrimination value was: $d=\mathrm{U}_{\mathrm{p}}-\mathrm{L}_{\mathrm{p}} / \mathrm{U}$; where $\mathrm{U}_{\mathrm{p}}$ and $\mathrm{L}_{\mathrm{p}}$ indicates the number of respondents in the upper and lower groups who pass the item and $U$ is the total number of respondents in the upper group. Using the formula, the discrimination values were calculated for all the items of the test, and are presented in Table 1. Based on the cut-off range according to Ebel and Frisbie (1986), items with discrimination value below .19 are considered as 'poor' items needing revision. Accordingly item numbers $1(d=0.12)$, item number $6(d=$ $0.17)$ were dropped. Although the item number 7 had a low discrimination value $(d=0.17)$ was retained because of its theoretical importance. Thus after dropping two items, the final form of Hypertension Knowledge Test had 22 items.

Description of Hypertension Knowledge Test: The newly developed test after item analysis consisted of 22 items written in statement format and each given a set of five options of which only one option was a correct. The correct response was given a score of 1 and the wrong responses and the responses of 'do not know' were given zero score. The 22 items were distributed under the following four domains on the agreement of the expert panel of two medical doctors and a Health Psychologist. The domains consisted of knowledge related to General awareness of hypertension (five items), lifestyle factors in hypertension care (five items), Causes, Care and Casualty awareness (six items), medication management (6 items). With this, the development of the test is completed. In order to establish the psychometric properties of the test, the phases of reliability and validity testing were followed.

\section{PHASE III-RELIABILITY}

In this phase, we planned to examine the reliability coefficient of the hypertension knowledge test by testing on a fresh sample of 130 hypertensive patients. The stability of the instrument over time was tested by the test-retest reliability method. 


\section{METHOD}

\section{Participants}

The inclusion criteria were same as in phase II with an additional criterion of patient's consent of willingness to attend the health Centre twice with a gap of 50 days period. After attrition, 117 out of 130 (90\%) patients attended the retesting session. This sample of 117 comprised of men (51.3\%) and women(48.7 \%). The sample had school dropout (12\%), high school education (48.7\%) and Graduation or above (39.3\%). The age range was 30-65 years $(M=51.50, S D=8.70)$. The mean duration of illness was 6.11 years $(S D=5.16)$.

\section{Procedure}

Administrative permission and informed consent were obtained from the health center of the church. The patients enrolled in the health Centre were contacted. Those who were willing to sign the informed consent and are willing to attend the health center twice with a gap of 50 days were recruited for the study. The participants were administered the 22 item Hypertension Knowledge Test on the first visit in group setting. After a gap of fifty days of initial administration, the same scale was re administered to the same group to ensure the testretest reliability. Pearson's product moment correlation coefficient was used to measure the level of agreement between responses at test and re-test.

\section{RESULTS}

Pearson's product moment correlation coefficient was used to measure the level of agreement between responses at test and re-test. A high positive correlations were observed between the total scores $(r=0.87, \mathrm{P}<0.001)$. Similarly high positive correlations were also observed between test retest scores among each dimension of General Awareness ( $r=0.91, \mathrm{P}<0.001$ ), lifestyle ( $r=0.68, \mathrm{P}<0.001)$, Causes, care, casualty awareness $(r=0.90, \mathrm{P}<0.001)$, and Medication management $(=.75, \mathrm{P}<.001)$. These values establish high reliability of the test.

\section{PHASE IV-VALIDITY}

We intended to establish criterion validity, where Hypertension Knowledge Test scores would be expected to match the scores of existing tools. Nonetheless, we could not trace a multidimensional similar test having uniform response pattern in literature. As an alternative, the construct such as blood pressure control that tends to have negative relationship with the construct of knowledge of hypertension (see Introduction) was considered for validity testing. Therefore, we explored the construct validity with the blood pressure readings assuming that high knowledge levels negatively correlating with the B.P readings indicate the validity of the test as has been used in the past research (Han et al., 2011; Panditet al., 2009;Wang et al., 2003; Xuet al., 2014)

\section{METHOD}

\section{Participants}

A fresh sample of 347 patients with hypertension was recruited following a convenience sampling. The participants were recruited for the study following the same inclusion criteria described in phase II. The participants were administered the 22 item Hypertensive 


\section{Hypertension Knowledge Test: Development and Validation}

Knowledge Test. The blood pressure readings of the participants were measured by the physician at the church health Centre. The sample consisted of men (53.3\%) and women (46.7 \%). The sample had school dropout (17.6\%), high school education (47\%) and Graduation and above (35.4\%). The age range was 30-65 years $(M=52.20, S D=8.69)$. The mean duration of illness was 5.61 years $(S D=5.16)$.

\section{Procedure}

The standard administrative and ethical procedures were followed in recruiting patients. The participants' blood pressure was checked and recorded at the Church Health Centreby the mercury sphygmomanometer by the physician by following standard procedures where the patient was asked to be comfortably seated for 30 minutes. BP was recorded by averaging the three B.P readings taken in succession with the gap of 10 minutes each. Thereafter the hypertension Knowledge test was administered. The assessments took 60 to 70 minutes for each participant.

\section{RESULTS}

Construct validity for the Hypertension Knowledge Test was assessed by testing the relationship between Hypertension knowledge and B.P control. The scores on the Hypertension Knowledge Test were correlated with Systolic Blood Pressure and Diastolic Blood Pressure values. A statistically significant inverse relationship was obtained between Hypertension knowledge and Systolic Blood Pressure ( $\mathrm{r}=-.30, \mathrm{p}=0.001$ ), as well as Hypertension knowledge and Diastolic Blood Pressure ( $r=-.28, \mathrm{p}=0.001)$.Further, the sample was divided into two groups based on the Joint National Committee's (JNC-8) guidelines for diagnosis of Hypertension in adults (James et al., 2014). The participants with blood pressure lesser than 140/90 mm/hg were grouped under 'controlled B.P' and the participants whose blood pressure reading was equal to or higher than 140/90 mm/hg were grouped under 'uncontrolled B.P'. An independent-samples t-test was conducted to compare the groups with controlled B.P and uncontrolled B.P on the Hypertension knowledge score. As hypothesized, those with controlled BP $(M=13.76, S D=3.41)$ had significantly higher levels of Hypertension knowledge scores than those with uncontrolled B.P. $(M=11.98, S D=4.14) ; t(345)=4.28, p<$ 0.01 . The construct validity of Hypertension Knowledge Test can be inferred from the above results.

\section{DISCUSSION}

A 22 item test for the assessment of a patient's level of knowledge has thus been developed and standardized to be used for hypertensive, pre-hypertensive and normotensive patients. The standardization is done both in English and local language. The test is developed as a screening tool to design and plan any educational interventions to improve the knowledge of the patients thereby enabling the patients to be active participant in the chronic disease management of the hypertension. The four domains of the test measures the knowledge specific to each area of the management of hypertension such as knowledge pertaining to the general awareness of the disease condition, the knowledge related to the lifestyle factors influencing hypertension and its management, the dietary regimen and exercise regulation, 


\section{Hypertension Knowledge Test: Development and Validation}

the causes, care and casualty awareness of the hypertension, the medication management are covered in detail thereby the comprehensive knowledge required to empower patients' active participation in disease management can be assessed by the test. The scores in each dimension can throw light on the multidimensional knowledge related to hypertension care. Low scores in the dimension of knowledge related to lifestyle factors can help the Health Psychologists to educate the hypertensive patients by providing lifestyle modification interventions which have a profound impact on the management of primary hypertension (Elmeret al., 2006), which has also been recommended by 'the National Institute for Health and Clinical Excellence's (NICE) guidelines for hypertension management (Krauseet al., 2011).

\section{Implications of the study}

Hypertension knowledge test can be used effectively for clinical and research purposes. The tool is a comprehensive yet, short and user friendly form where the patient does not get fatigue in answering 22 questions with multiple choice answers. In countries where the doctor patient ratio is abysmally disproportionate, as in India where it is 1:1800 (Deo, 2013), the tool can aid in screening the patients scoring low on hypertension knowledge. Further, these patients can be recommended for group educational and counseling programs. This reduces lot of consultation time for the doctors and also empowers the patient in active management of their disease condition. The scale can be used by the nurses during the initial screening and assessment preceding consultation with the physician. This facilitates the physician's health communication with the patients in appraising them of their disease condition and the significance of adherence. The physician can focus his/her communication on the dimensions where the knowledge of the patient is weak. The test can also be used in the context of public health endeavors where the knowledge levels of community prior to introduction of the intervention can be assessed. In addition, in view of alarming future projections of hypertension, the test can be administered on children and youth to assess their levels of knowledge in hypertension so that interventions aiming at enhancing awareness can be planned based on their existing levels of knowledge and misconceptions. The tool helps the Health Psychologist in planning the patient lifestyle modification counseling sessions. The knowledge domain profiling of the patient would empower interventional studies to tailor the interventions based on individual/group need. Assessing the varied domains of the knowledge of the patient and providing the interventions accordingly, enables the health care industry in transiting to the much advocated patient centered and holistic approach.

\section{Limitations of the study}

The Hypertension Knowledge Test, though stood the robust test of psychometric assessments is standardized on a sample in one geographical area. Hence there is a need to test its validity on a larger sample through a multicenter project. This will also facilitate standardization of the tool on a few other languages apart in addition to English and of local language. 


\section{CONCLUSION}

The present form of the Hypertension Knowledge Test is recommended for assessment of Hypertension knowledge in any population. This can be used as a preliminary screening test in individual clinical setting as well as groups as an assessment tool for any population. Thus this test is an aid for clinical practitioners as well as researchers.

\section{Conflict of interest}

The Authors declare that there is no conflict of interest

\section{Acknowledgments}

Our sincere thanks to all the patients and management of the church. We also thank the subject experts for their timely help and suggestions during the development of the test.

\section{Funding}

The study is part of the Ph.D work which is funded by UGC-MANF with the approval number of 201213-MANF-2012-13-CHR-AND-14166

\section{REFERENCES}

Alm-Roijer, C., Stagmo, M., Udén, G., \& Erhardt, L. (2004). Better knowledge improves adherence to lifestyle changes and medication in patients with coronary heart disease. European Journal of Cardiovascular Nursing, 3(4), 321-330.

Anchala, R., Kannuri, N. K., Pant, H., Khan, H., Franco, O. H., Di Angelantonio, E., \& Prabhakaran, D. (2014). Hypertension in India: a systematic review and meta-analysis of prevalence, awareness, and control of hypertension. Journal of hypertension, 32(6), 1170.

BalizErkoc, S., Isikli, B., Metintas, S., \& Kalyoncu, C. (2012). Hypertension KnowledgeLevel Scale (HK-LS): a study on development, validity and reliability. International journal of environmental research and public health, 9(3), 1018-1029.

Bender, B. G., \& Bender, S. E. (2005). Patient-identified barriers to asthma treatment adherence: responses to interviews, focus groups, and questionnaires. Immunology and allergy clinics of North America, 25(1), 107-130.

Bodenheimer T, Wagner EH, Brumbach K. Improving primary care for patients with chronic illness. JAMA. 2002;288:1909-1914

Coleman, K., Austin, B. T., Brach, C., \& Wagner, E. H. (2009).Evidence on the chronic care model in the new millennium. Health affairs, 28(1), 75-85.

Crocker, L., \&Algina, J. (1986). Introduction to classical and modern test theory. Holt, Rinehart and Winston, 6277 Sea Harbor Drive, Orlando, FL 32887.

Deo, M. G. (2013). Doctor population ratio for India-The reality. The Indian journal of medical research, 137(4), 632.

Ebel, R. L.,Frisbie, D.A. (1986). Essential of Educational Measurement.

Elmer, P. J., Obarzanek, E., Vollmer, W. M., Simons-Morton, D., Stevens, V. J., Young, D. R., ...\&Ard, J. (2006). Effects of Comprehensive Lifestyle Modification on Diet, Weight, Physical Fitness, and Blood Pressure Control: 18-Month Results of a Randomized TrialPREMIER 18-Month Results. Annals of internal medicine, 144(7), 485-495.

Gaziano, T. A., Bitton, A., Anand, S., \& Weinstein, M. C. (2009).The global cost of nonoptimal blood pressure. Journal of hypertension, 27(7), 1472-1477. 
Ghembaza, M. A., Senoussaoui, Y., KendouciTani, M., \& Meguenni, K. (2014).Impact of patient knowledge of hypertension complications on adherence to antihypertensive therapy. Current hypertension reviews, 10(1), 41-48.

Han, H. R., Chan, K., Song, H., Nguyen, T., Lee, J. E., \& Kim, M. T. (2011). Development and evaluation of a hypertension knowledge test for Korean hypertensive patients. The Journal of Clinical Hypertension, 13(10), 750-757.

Hariharan, M., Chivukula, U., \&Rana, S. (2015). The intensive care unit psychosocial care scale: Development and initial validation. Intensive and Critical Care Nursing, 31(6), 343-351.

Hariharan, M., Thomas, M., \&Rana, S. (2015). The adherence scale for cardiac patients: Development and initial testing. Indian Journal of Health and Wellbeing, 6(10), 936.

James, P. A., Oparil, S., Carter, B. L., Cushman, W. C., Dennison-Himmelfarb, C., Handler, J., ...\& Smith, S. C. (2014). 2014 evidence-based guideline for the management of high blood pressure in adults: report from the panel members appointed to the Eighth Joint National Committee (JNC 8). Jama, 311(5), 507-520.

Kelley, T. L. (1939). The selection of upper and lower groups for the validation of test items. Journal of educational psychology, 30(1), 17.

Krause, T., Lovibond, K., Caulfield, M., McCormack, T., Williams, B., \& Guideline Development Group. (2011). Management of hypertension: summary of NICE guidance. Bmj, 343, d4891.

Kusuma, Y. S., Gupta, S. K., \&Pandav, C. S. (2009).Knowledge and perceptions about hypertension among neo-and settled-migrants in Delhi, India. CVD Prevention and Control, 4(2), 119-129.

Lawson, V. L., Lyne, P. A., Harvey, J. N., \& Bundy, C. E. (2005). Understanding why people with type 1 diabetes do not attend for specialist advice: a qualitative analysis of the views of people with insulin-dependent diabetes who do not attend diabetes clinic. Journal of health psychology, 10(3), 409-423.

Lim, S. S., Vos, T., Flaxman, A. D., Danaei, G., Shibuya, K., Adair-Rohani, H., ...\&Aryee, M. (2013). A comparative risk assessment of burden of disease and injury attributable to 67 risk factors and risk factor clusters in 21 regions, 1990-2010: a systematic analysis for the Global Burden of Disease Study 2010. The lancet, 380(9859), 22242260.

Mahal, A. S., Karan, A., \&Engelgau, M. (2010).Economic Implications of Noncommunicable Disease for India. Washington, DC: World Bank.

Pandit, A. U., Tang, J. W., Bailey, S. C., Davis, T. C., Bocchini, M. V., Persell, S. D., ... \& Wolf, M. S. (2009). Education, literacy, and health: Mediating effects on hypertension knowledge and control. Patient education and counseling, 75(3), 381-385.

Peters, R. M., \& Templin, T. N. (2008).Measuring blood pressure knowledge and self-care behaviors of African Americans. Research in nursing \& health, 31(6), 543-552.

Ponnusankar, S., Surulivelrajan, M., Anandamoorthy, N., \& Suresh, B. (2004).Assessment of impact of medication counseling on patients' medication knowledge and compliance in an outpatient clinic in South India. Patient education and counseling, 54(1), 55-60.

Ramachandran, H. J., Wu, V. X., Kowitlawakul, Y., \& Wang, W. (2016). Awareness, knowledge and healthy lifestyle behaviors related to coronary heart disease among women: An integrative review. Heart \& Lung: The Journal of Acute and Critical Care, 45(3), 173-185.

Rosenbaum, M. (1990).The role of learned resourcefulness in the self-control of health behavior.

Sanne, S., Muntner, P., Kawasaki, L., Hyre, A., \&DeSalvo, K. B. (2008). Hypertension knowledge among patients from an urban clinic.Ethnicity and Disease, 18(1), 42. 


\section{Hypertension Knowledge Test: Development and Validation}

Schapira, M. M., Fletcher, K. E., Hayes, A., Eastwood, D., Patterson, L., Ertl, K., \& Whittle, J. (2012). The development and validation of the hypertension evaluation of lifestyle and management knowledge scale. The Journal of Clinical Hypertension, 14(7), 461466.

Shaikh, R. B., Mathew, E., Sreedharan, J., Muttappallymyalil, J., Al Sharbatti, S., \&Basha, S. A. (2011).Knowledge regarding risk factors of hypertension among entry year students of a medical university. Journal of Family and Community Medicine, 18(3), 124.

Test Your Blood Pressure IQ. (2017). Heart.org. Retrieved 17 October 2017, from http://www.heart.org/HEARTORG/Conditions/HighBloodPressure/AboutHighBlood

Pressure/Test-Your-Blood-Pressure-IQ_UCM_303313_Article.jsp\#.WeXcMmiCwb4

University of Maryland Medical Center (2012).In-depth patient education report. Retrieved October 15, 2017, from http://www.umm.edu/health/medical/reports/articles/highblood-pressure

Viera, A. J., Cohen, L. W., Mitchell, C. M., \& Sloane, P. D. (2008). High blood pressure knowledge among primary care patients with known hypertension: a North Carolina Family Medicine Research Network (NC-FM-RN) study. The Journal of the American Board of Family Medicine, 21(4), 300-308.

Wang, X., Bai, H. F., Ma, K. M., Li, B., Qi, J. H., Chen, B. J., ...\& Yu, X. W. (2003). Relationship between the patients' knowledge on hypertension prevention and control and the rate on blood pressure control. Zhonghualiuxingbingxuezazhi Zhonghualiuxingbingxuezazhi, 24(12), 1082-1085.

Wexler, R., Elton, T., Taylor, C. A., Pleister, A., \& Feldman, D. (2009). Physician reported perception in the treatment of high blood pressure does not correspond to practice. BMC family practice, 10(1), 23.

Williams, M. V., Baker, D. W., Parker, R. M., \& Nurss, J. R. (1998). Relationship of functional health literacy to patients' knowledge of their chronic disease: a study of patients with hypertension and diabetes. Archives of internal medicine, 158(2), 166172.

World Health Organization. (2013). A global brief on hypertension: silent killer, global public health crisis: World Health Day 2013.a

Xu, L. J., Meng, Q., He, S. W., Yin, X. L., Tang, Z. L., Bo, H. Y., \&Lan, X. Y. (2014). The effects of health education on patients with hypertension in China: A meta-analysis. Health Education Journal, 73(2), 137-149.

How to cite this article: Andrew A, \& Hariharan M (2017). Hypertension Knowledge Test: Development and Validation. International Journal of Indian Psychology, Vol. 5, (1), DIP: 18.01.045/20170501, DOI: 10.25215/0501.045 